\title{
Erythrocyte aggregation as an early biomarker in patients with asymptomatic carotid stenosis
}

\author{
Einor Ben Assayag ${ }^{\mathrm{a}, 1}$, Irena Bova ${ }^{\mathrm{a}}$, Anat Kesler ${ }^{\mathrm{a}}$, Shlomo Berliner ${ }^{\mathrm{b}}$, Itzhak Shapira ${ }^{\mathrm{b}}$ and \\ Natan M. Bornstein ${ }^{\mathrm{a}, 1, *}$ \\ ${ }^{a}$ Department of Neurology, Tel Aviv Sourasky Medical Center affiliated to Sackler Faculty of Medicine, Tel Aviv \\ University, Tel Aviv, Israel \\ ${ }^{\mathrm{b}}$ Department of Medicine “D”, Tel Aviv Sourasky Medical Center affiliated to Sackler Faculty of Medicine, Tel Aviv \\ University, Tel Aviv, Israel
}

\begin{abstract}
Background: Atherosclerosis is a chronic inflammatory disease.
Design: We have evaluated the degree of erythrocyte aggregation (EA) as a microinflammatory biomarker in a cohort of hospital-based, neurologically asymptomatic outpatients.

Methods: The degree of EA and carotid artery stenosis was evaluated in 510 individuals by using a simple slide test and image analysis.

Results: Four hundred and sixteen individuals had minimal carotid stenosis $(<30 \%)$; 47 had mild to moderate stenosis $(30-69 \%)$ and 47 had severe stenosis $(>70 \%)$. A significant correlation was noted between the degree of carotid stenosis and the erythrocyte sedimentation rate (ESR), white blood cell count (WBCC) and fibrinogen $(r=0.160, p=0.005 ; r=0.191, p=0.001$ and $r=0.126, p=0.026$, respectively). The significant correlation was noted between the degree of carotid stenosis and EA ( $r=$ $0.209, p<0.001)$. The subjects with severe stenosis differed significantly from the other groups in their ESR, WBCC and EA. High sensitivity C-reactive protein (hs-CRP) concentrations did not discriminate between the presence and absence of significant carotid atherosclerotic disease.

Conclusions: Inflammatory biomarkers such as ESR and the EA test are more sensitive than hs-CRP to the presence of a significant atherosclerotic carotid burden. These biomarkers might aid in the detection and quantification of microinflammation in individuals with carotid atherosclerosis.
\end{abstract}

Keywords: Carotid atherosclerosis, C-reactive protein, microinflammation, erythrocyte aggregation

\section{Introduction}

Recent studies have questioned the usefulness of high sensitivity C-reactive protein (hs-CRP) for the detection and quantification of the microinflammatory response that is associated with the atherosclerotic disease [1-3]. We have recently introduced a new

\footnotetext{
${ }^{1}$ Einor Ben Assayag and Natan M. Bornstein should both be considered first authors.

* Corresponding author: Prof. Natan M. Bornstein, MD, Head, Department of Neurology, Tel-Aviv Sourasky Medical Center, 6 Weizman Street, Tel Aviv 64239 Israel. Tel.: +972 3 6973159; Fax: +972 3 6973146; E-mail: strokeun@tasmc.health.gov.il.
}

biomarker that uses the patient's erythrocytes as sensors for the presence of acute phase response adhesive proteins in the peripheral venous blood [4-6]. The aim of the present study was to analyze the results of this biomarker in relation to the degree of carotid artery stenosis, as a surrogate marker for the atherosclerotic disease.

\section{Materials and methods}

\subsection{Study subjects}

We have included neurologically asymptomatic subjects who were in routine follow up in the various out- 
patient clinics of the Medical Center between February 2001 and September 2004, including diabetes, hypertension, metabolic disorders and dyslipidemia clinics. Excluded were individuals with known inflammatory diseases (arthritis, inflammatory bowel disease), history of cerebral or cardiac event during the last 12 months, history of acute febrile disease or infection during the last 3 months, known malignancy, pregnancy, steroidal or nonsteroidal treatment (except for aspirin at a dose of $\leqslant 325 \mathrm{mg} / \mathrm{dl}$ ), and invasive procedures (surgery, catheterization, etc.) during the last 6 months. All participants signed a written informed consent, approved by the Ethical Committee of the Medical Center.

\subsection{Definitions of risk factors}

Diabetes mellitus was defined as a fasting blood glucose of $\geqslant 126 \mathrm{mg} / \mathrm{dl}$ or the use of insulin or oral hypoglycemic agents; hypertension as blood pressures of $\geqslant 140 / 90 \mathrm{mmHg}$ or the use of anti-hypertensive medications; hyperlipidemia as cholesterol concentrations of $\geqslant 200 \mathrm{mg} / \mathrm{dl}$ or the use of HMG-CoA reductase inhibitors or fibrates. Current smokers as well as past smokers (had not smoked for the last 30 days or more) were also included.

\subsection{Carotid Doppler ultrasound}

Carotid artery stenosis was determined by ultrasonographic measurement of the internal carotid arteries. Ultrasonographic scanning was performed using carotid duplex equipment (128XP/10, Acuson) with a $7.5 \mathrm{MHz}$ linear array transducer; focus depth of $40 \mathrm{~mm}$ and frame rate of $15 \mathrm{~Hz}$. Internal carotid artery (ICA) stenosis was minimal when peak systolic velocity (PSV) was less than $145 \mathrm{~cm} / \mathrm{sec}$ and no plaque or intimal thickening was visible. ICA PSV of at least $125 \mathrm{~cm} / \mathrm{s}$ was the threshold for a $50 \%$ stenosis; $50 \%-69 \%$ stenosis was defined as ICA PSV of 125$230 \mathrm{~cm} / \mathrm{sec} ; \geqslant 70 \%$ stenosis was defined as ICA PSV of $\geqslant 230 \mathrm{~cm} / \mathrm{sec}$ with visible plaque and lumen narrowing; near occlusion when there is a markedly narrowed lumen, and total occlusion when there is no flow [7]. "Total atherosclerotic burden" of the carotid arteries was arbitrarily defined as the sum of the degree of stenosis in both the right and the left carotid arteries.

Subjects were divided into three groups according to the median of their sum degree of stenosis in both arteries: minimal stenosis or none (0-20\%), mild-moderate stenosis (20.1-77.5\%), severe stenosis (77.6-200\%), where $200 \%$ was defined as occlusion of both ICAs.
The intima-media thickness (IMT), defined as the distance between the intimal-luminal interface and the medial-adventitial interface. We calculated the mean carotid artery IMT (mean IMT) by averaging the thickness at 4 sites at the far walls of both the right and left distal common carotid artery.

The subjects were also classified according to the presence of well-defined atherosclerotic plaques. Plaques were defined as a focal structure that encroaches into the arterial lumen of at least $0.5 \mathrm{~mm}$ or $50 \%$ of the surrounding IMT value or demonstrates a thickness of $\geqslant 1.5 \mathrm{~mm}$ as measured from the media-adventitia interface to the intima-lumen interface.

\subsection{Inflammation biomarkers}

The white blood cell count (WBCC) and differential were performed by using the Coulter STKS electronic counter, erythrocyte sedimentation rate (ESR) by the method of Westergen [8], fibrinogen concentrations by the method of Clauss [9] while the hs-CRP concentrations were performed according to Rifai [10]. The erythrocyte aggregation test (EAT) was performed by using a simple slide test and image analysis [11]. In brief, blood was drawn into a syringe containing sodium citrate (one volume of $3.8 \%$ sodium citrate and three volumes of whole blood). A drop of blood was placed on a slide, held for 2 to 3 seconds at a $45^{\circ}$ angle so that the blood could run down, leaving a fine film. The slides were then dried in a completely horizontal position, at room temperature. In order to determine the degree of EAT, we defined a parameter in the name of "vacuum radius" (VR), representing the typical size (in microns) of a blank space formed on the slides during increased erythrocyte aggregation [12]. Another variable was the erythrocyte percentage (EP) which represents the area covered on the slides by erythrocytes. For example, if there is no aggregation, cells cover $100 \%$ of the slide. When cells begin to aggregate, free spaces are created between the aggregates and the above mentioned percentage is reduced. Variability of this method is given elsewhere [13-15].

\subsection{Statistical analysis}

All continuous data were summarized and displayed as mean \pm SD. Since only hs-CRP values have a nonnormal distribution, a logarithmic transformation was employed and all results expressing hs-CRP values were back-transformed to geometric means \pm SD. De- 
Table 1

Population characteristics, including atherothrombotic risk factors and past history of vascular events

\begin{tabular}{|c|c|c|c|c|}
\hline & $\begin{array}{c}\text { Minimal } \\
\text { Stenosis } \\
\mathrm{N}=416\end{array}$ & $\begin{array}{c}\text { Mild - } \\
\text { Moderate } \\
\text { Stenosis } \\
\mathrm{N}=47\end{array}$ & $\begin{array}{c}\text { Severe } \\
\text { stenosis } \\
\mathrm{N}=47\end{array}$ & $\mathrm{p}$ ANOVA \\
\hline Males, n (\%) & $190(45.7)$ & $25(53.2)$ & $29(61.7)$ & 0.092 \\
\hline Age, mean (SD) & $65.9(9.9)$ & $69.7(10.3)$ & $74.1(7.1)$ & $<0.001$ \\
\hline Mean BMI Kg/m² (SD) & $26.8(4.8)$ & $26.1(4)$ & $25.7(3.5)$ & 0.213 \\
\hline Hypertension, \% & 44 & 51.1 & 76.6 & $<0.001$ \\
\hline Smoking (past \& present), $\%$ & 43 & 40.4 & 53.2 & 0.368 \\
\hline Diabetes mellitus, $\%$ & 14.4 & 27.7 & 34 & 0.001 \\
\hline \multicolumn{5}{|l|}{ History of MI, \% } \\
\hline 4.1 & 4.3 & 8.5 & 0.382 & \\
\hline History of CABG, \% & 7.9 & 17 & 34 & $<0.001$ \\
\hline History of stroke, $\%$ & 0.2 & 12.8 & 10.6 & $<0.001$ \\
\hline History of TIA, \% & 1.7 & 4.3 & 0 & 0.281 \\
\hline History of PVD, \% & 0.7 & 8.5 & 4.3 & $<0.001$ \\
\hline Mean IMT* ${ }^{*}$ mm (SD) & $0.81(1.14)$ & $0.86(1.13)$ & $0.9(1.15)$ & $<0.001$ \\
\hline \multicolumn{5}{|l|}{ Intake of medications } \\
\hline Aspirin, $\%$ & 36.8 & 66 & 83 & $<0.001$ \\
\hline Statins, $\%$ & 28.4 & 34 & 51.1 & 0.006 \\
\hline Hormonal therapy, $\%$ & 19.7 & 14.9 & 8.5 & 0.139 \\
\hline$\alpha$-blockers, $\%$ & 3.8 & 6.4 & 14.9 & 0.004 \\
\hline$\beta$-blockers, $\%$ & 19.5 & 29.8 & 29.8 & 0.088 \\
\hline Ca-blockers, $\%$ & 14.9 & 31.9 & 44.7 & $<0.001$ \\
\hline ACE-inhibitors, $\%$ & 17.1 & 27.7 & 40.4 & $<0.001$ \\
\hline ARB's, \% & 1.4 & 4.3 & 0 & 0.224 \\
\hline Fibrates, \% & 2.6 & 4.3 & 8.5 & 0.098 \\
\hline
\end{tabular}

mographic and clinical data between groups were compared by the $\chi^{2}$ test and student's $t$ test.

Correlations between the different inflammatory biomarkers and carotid stenosis were determined using the two tailed-Pearson correlation.

Differences between groups were evaluated using analysis of variance (ANOVA), post hoc comparisons or the student t test. Finally, the student's $t$ test and the Mann-Whitney U test were applied to test the difference in the inflammatory biomarkers and EA variables between subjects carrying plaques in their carotid arteries and non-plaque subjects.

$p<0.05$ was considered statistically significant.

All analyses were carried out using SPSS (SPSS Inc., Chicago, IL, USA) software version 13.0.

\section{Results}

A total of 510 subjects were examined; 416 had minimal carotid stenosis or none, 47 had mild to moderate stenosis while 47 had severe carotid stenosis. The mean \pm SD age, gender, body mass index (BMI), IMT measures and intake of medications are reported in Table 1. Included in this table are the vascular risk factors as well as past history of vascular events. As expected, individuals with carotid disease had more frequent vascular risk factors and had experienced more vascular events in the past.

There was an increase in the intake of cardiovascular active drugs in individuals with carotid stenosis. On the other hand, the percentage of women on hormonal replacement therapy was lower in the group with carotid stenosis.

Results of the hematological, biochemical and EAT as well as inflammatory biomarkers are reported in Table 2. The three groups differed significantly in their ESR, WBCC and the EA ( $p$ for trend $=0.001$, Dunnett T3 between minimal to severe: $p=0.004 ; p$ for trend $=0.037$, Dunnett T3 between minimal to severe: $p=$ $0.01 ; p$ for trend $<0.001$, Dunnett T3 between minimal to severe: $p=0.004$, between moderate to severe: $p=$ 0.039, respectively, Table 2 and Figs 1,2). Of interest is the observation that concentrations of hs-CRP did not 
Table 2

Biochemical and erythrocyte aggregation parameters of study participants, mean (SD) plus one-way ANOVA and the Dunnett T3 multiple comparisons between the groups

\begin{tabular}{lcccc}
\hline & $\begin{array}{c}\text { Minimal } \\
\text { Stenosis (0) } \\
\mathrm{N}=416\end{array}$ & $\begin{array}{c}\text { Mild }- \\
\text { Moderate } \\
\text { Stenosis (1) } \\
\mathrm{N}=47\end{array}$ & $\begin{array}{c}\text { Severe } \\
\text { stenosis (2) } \\
\mathrm{N}=47\end{array}$ & p ANOVA \\
& & & \\
\hline Hemoglobin $(\mathrm{g} / \mathrm{dL})$ & $13.8(1.2)$ & $13.5(1.2)$ & $13.3(1.1)$ & 0.024 \\
Hematocrit $(\%)$ & $40.3(3.4)$ & $39.6(3.7)$ & $39.4(3)$ & 0.132 \\
Total cholesterol (mg/dL) & $215.1(37.8)$ & $213.8(43.9)$ & $198(31.4)$ & 0.020 \\
LDL-cholesterol (mg/dL) & $133.6(32)$ & $133.3(37)$ & $120.4(32.1)$ & 0.040 \\
HDL-cholesterol (mg/dL) & $56.6(15.8)$ & $54.5(15.8)$ & $47.6(9.6)$ & 0.001 \\
ESR $(\mathrm{mm} / \mathrm{H})$ & $20.2(14.8)$ & $22.5(13.5)$ & $29.6(17.3)$ & 0.001 \\
hs-CRP $(\mathrm{mg} / \mathrm{L})^{*}$ & $1.54(0.71)$ & $1.5(0.58)$ & $1.68(0.9)$ & 0.604 \\
Fibrinogen $(\mathrm{g} / \mathrm{dL})$ & $306.4(60.3)$ & $310.3(51.1)$ & $326.4(56.5)$ & 0.099 \\
WBCC $\left(\mathrm{x} 10^{3} / \mu \mathrm{L}\right)$ & $6.8(1.7)$ & $7(1.8)$ & $7.5(1.4)$ & 0.037 \\
VR $(\mu \mathrm{m})$ & $7.4(6.2)$ & $8(5.3)$ & $11.6(8.3)$ & $<0.0001$ \\
EP $(\%)$ & $82.1(15.3)$ & $79.9(14.4)$ & $73.3(15.9)$ & 0.001 \\
\hline
\end{tabular}

ESR: erythrocyte sedimentation rate; hs-CRP: high sensitivity C-reactive protein; WBCC:, white blood cells count; HDL: high-density lipoprotein; LDL: low- density lipoprotein; EP: erythrocyte percentage; VR: vacuum radius.

*Data were logarithmically transformed before analysis, presented is the geometric mean (SE).

reach statistical significance when analyzing the differences between the groups. When comparing the mild to moderate and severe stenosis groups, a significant difference was noted in their ESR and EA ( $p=0.036$; $p=0.013$, respectively).

We performed an age, gender, BMI and hematocrit adjusted correlation between the degree of carotid stenosis and the inflammatory biomarkers. The results indicate that only a weak correlation exists between the degree of stenosis and ESR, WBCC, fibrinogen concentrations and EA measurements, EP and VR $(r=0.160, p=0.005 ; r=0.191, p=0.001$; $r=0.126, p=0.026 ; r=-0.179, p=0.002 ; r=$ $0.209, p<0.001$, respectively), but patients with significant carotid stenosis have higher levels of the studied biomarkers. Also, weak correlation observed between mean carotid IMT and WBCC $(r=0.228, p=$ $0.015)$, but not with the other biomarkers.

Finally, carotid plaques formation in our population was associated with elevated concentrations of the inflammatory biomarkers fibrinogen, ESR, CRP, WBCC and the EAT in men only (Table 3).

\section{Discussion}

Recent studies have suggested that atherosclerosis is a chronic inflammatory disease [16]. hs-CRP assays have been widely used in the detection and quantification of microinflammation in atherosclerotic and apparently healthy individuals. Yet conflicting results exist regarding the correlation between the atherosclerotic burden and concentration of this protein [17-23]. Thus, additional biomarkers are constantly evaluated for the purpose of microinflammation detection and quantification in these populations.

We have presently examined the carotid artery disease as a surrogate marker for the presence of an atherothrombotic disease.

In order to obtain a semi-quantitative evaluation regarding the severity of the disease, the degree of stenosis was evaluated in both carotid arteries and the results summarized. The percentage of stenosis can thus be considered as a score illustrating the burden of the disease. For example, a person with stenosis of $60 \%$ in one carotid artery and $70 \%$ in the other one scored 130. Using this mode of scoring, one can obtain a measurement that relates to the burden of carotid artery atherosclerotic disease.

Our study demonstrated that a moderate correlation exists between the above mentioned score and all five inflammatory biomarkers herein reported. Of special interest is that the EAT had the highest correlation (Table 4). Moreover, when the three groups of minimal, mild to moderate and severe stenosis were analyzed by ANOVA, only the ESR, WBCC and the EAT reached statistical significance. In addition, by performing a ttest between the two groups of mild to moderate and severe stenosis, only ESR and EAT reached significance.

Plaque formation was associated with elevated concentrations of the inflammatory biomarkers fibrinogen, ESR, WBCC and the EAT. The association between 
a.

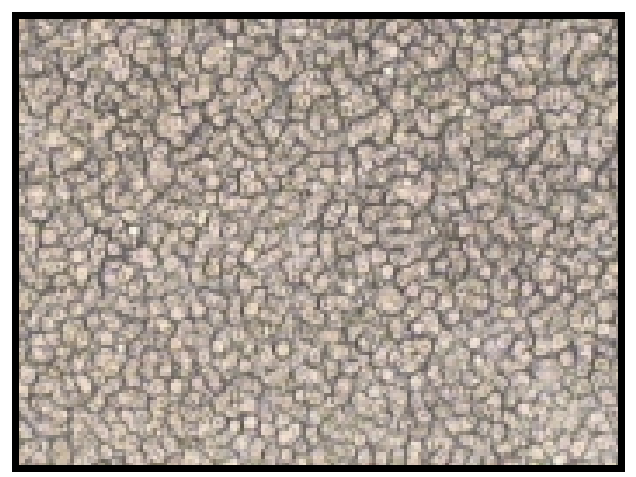

b.

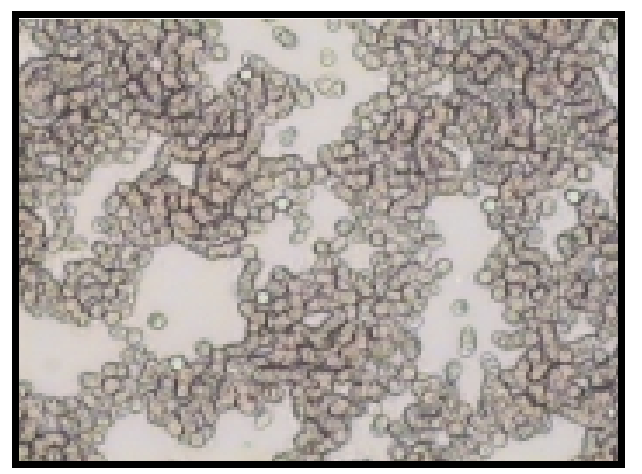

c.

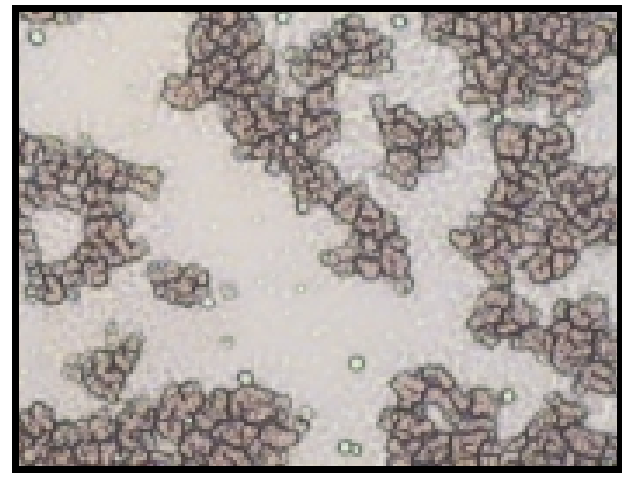

Fig. 1. Examples from individuals with minimal carotid stenosis or none (a), mild - to - moderate (b) and severe (c) carotid artery stenosis.

plaque formation and serum hs-CRP concentration was exclusively to men.

Overall, there are conflicting data on gender differences in the relationship between inflammation and atherosclerosis. Blackburn et al. reported that in dyslipidemic patients, elevated CRP is an independent predictor of advanced carotid plaques in male subject only [24]. Recent report of Makita et al has found association between CRP levels and carotid plaque formation in men but not women [25]. On the other hand, Wang et al analyzed data obtained from participants in the Framingham Study and reported a significant association between CRP and carotid atherosclerosis as measured by IMT in the internal carotid artery in women but not in men after adjustment for traditional cardiovascular disease risk factors [26].

These disagreements could be explained by differences in CRP levels between men and women. Khera et al reported higher CRP levels in women, after adjustment for traditional cardiovascular risk factors, estrogen and statin use [27]. Similar results were observed by our group as well [28].

It might be argued that hs-CRP concentrations are not significantly elevated in individuals with severe carotid stenosis due to the relatively high intake of medications with potential anti-inflammatory activities (aspirin, statins, ACE inhibitors, ARB's andfibrates). Moreover, the concentrations of hs-CRP might be relatively elevated in the minimal stenosis group due to hormonal replacement therapy (Table 2). The fact that the erythrocyte aggregation dependent biomarkers (ESR, EAT) remained significantly elevated is of special diagnostic relevance and may reveal underlying microinflammatory activity, when others (hs-CRP for example) are suppressed by commonly used cardiovascular active medications.

The erythrocyte aggregation test is mainly influenced by the presence of enhanced fibrinogen concentrations [11], although other proteins contribute as well [29], providing a measurement of the intererythrocyte cohesive forces [30]. The potential advantages of this test over the Westergren ESR have been presented in several clinical models [31-33]. Therefore, the test might be a relevant biomarker for detection of microinflammation in individuals with carotid atherosclerosis, especially in the absence of significantly enhanced hs-CRP concentrations.

We conclude that most commonly used simple inflammatory biomarkers, including the Westergren ESR, fibrinogen concentrations, WBCC and hs-CRP impart only a modest correlation with the degree of carotid artery stenosis, while the degree of erythrocyte aggregation as measured by our direct visualization presents a somewhat better correlation with the degree of carotid artery stenosis.

Hs-CRP concentrations did not discriminate between the presence and absence of significant carotid atherosclerotic disease. The possibility that this is a result of intake of medications with an anti-inflammatory effect can not be excluded at the moment. Erythrocyte aggregation based tests such as Westergren's ESR or our slide test might be further evaluated as potential candidates in revealing the underlying atherosclerotic 
Table 3

Biochemical and erythrocyte aggregation parameters of the carotid plaque/s and non-plaque subjects mean (SD)

\begin{tabular}{|c|c|c|c|c|c|c|}
\hline & \multicolumn{3}{|c|}{ Men $n=244$} & \multicolumn{2}{|c|}{ Women $\mathrm{n}=266$} & \multirow[b]{2}{*}{$\begin{array}{c}\mathrm{p} \\
\text { t-test }\end{array}$} \\
\hline & $\begin{array}{c}\text { No plaque } \\
\mathrm{n}=105\end{array}$ & $\begin{array}{c}\text { Plaque } \\
\mathrm{n}=139\end{array}$ & $\mathrm{p}_{\text {t-test }}$ & $\begin{array}{c}\text { No plaque } \\
\mathrm{n}=146\end{array}$ & $\begin{array}{c}\text { Plaque } \\
\mathrm{n}=120\end{array}$ & \\
\hline $\mathrm{Hgb}, \mathrm{g} / \mathrm{dL}$ & $14.6(1.2)$ & $14(1.2)$ & 0.001 & $13.4(0.9)$ & $13.1(0.9)$ & 0.013 \\
\hline Hct $\%$ & $42.6(3.4)$ & $41(3.4)$ & 0.002 & $39.2(2.6)$ & $38.5(2.8)$ & 0.07 \\
\hline $\mathrm{ESR}, \mathrm{mm} / \mathrm{H}$ & $12.5(8.6)$ & $22.1(14.9)$ & $<0.0001$ & $22.6(13.9)$ & $26.3(17.9)$ & 0.07 \\
\hline $\mathrm{CRP}, \mathrm{mg} / \mathrm{L}^{*}$ & $1.25(1.6)$ & $1.41(1.5)$ & 0.037 & $1.44(1.6)$ & $1.48(1.5)$ & 0.66 \\
\hline $\mathrm{Fib}, \mathrm{g} / \mathrm{dL}$ & $286.6(54.7)$ & $312.9(63.6)$ & 0.001 & $310.9(55.7)$ & $320(58.3)$ & 0.20 \\
\hline WBC, $\left(\times 10^{3} / \mu \mathrm{L}\right)$ & $6.7(1.7)$ & $7.1(1.8)$ & 0.08 & $6.7(1.8)$ & $7(1.6)$ & 0.22 \\
\hline Total-C, mg/dL & $204.1(34.3)$ & $195.8(34.8)$ & 0.07 & $230(37.8)$ & $221.6(34.6)$ & 0.06 \\
\hline $\mathrm{HDL}-\mathrm{C}, \mathrm{mmol} / \mathrm{L}$ & $48.6(10)$ & $47.9(10.7)$ & 0.59 & $63.7(16.8)$ & $60.7(15.6)$ & 0.14 \\
\hline $\mathrm{LDL}-\mathrm{C}, \mathrm{mmol} / \mathrm{L}$ & $129.2(29.9)$ & $123.1(31.8)$ & 0.133 & $142(33.5)$ & $134(31.7)$ & 0.05 \\
\hline $\mathrm{EP} \%$ & $88.3(13.2)$ & $81.5(15.3)$ & $<0.0001$ & $79.1(15.7)$ & $76.6(15.1)$ & 0.18 \\
\hline $\mathrm{VR} \mu \mathrm{m}$ & $5.4(5)$ & $8(6.4)$ & $<0.0001$ & $8.5(7)$ & $9.1(6.4)$ & 0.46 \\
\hline
\end{tabular}

Hgb indicates hemoglobin; Hct, hematocrit; ESR, erythrocyte sedimentation rate; CRP, C-reactive protein; WBC, white blood cells; Total-C, total cholesterol; HDL-C, high-density lipoprotein-cholesterol; LDL, lowdensity lipoprotein-cholesterol; EP, erythrocyte percentage; VR, vacuum radius.

${ }^{*}$ Data were logarithmically transformed before analysis, presented is the geometric mean (SE).

microinflammatory process. Of special relevance is that hyperfibrinogenemia, enhanced red blood cell aggregation and the resulting hyperviscosity might have microcirculatory consequences for the distal tissue, in our case, the brain $[3,34,35]$. In the present study we analyzed the relations of a new inflammatory biomarker, erythrocyte aggregation based test, to the degree of carotid artery stenosis, as a surrogate marker for the atherosclerotic disease. Carotid artery disease is a wellestablished cause of cerebrovascular events. This risk is predicted by the severity of stenosis and other plaque characteristics that can be documented using imaging techniques [36]. Measuring clinical and systemic biochemical markers of risk, such as the erythrocyte aggregation based test, may assist to imaging techniques in recognizing the high-risk carotid plaque and could improve selection of treatment.

\section{Acknowledgments}

We would like to thank Mrs. Tanya Nissel and Mrs. Sigal Lorentz for the professional and dedicated assistance in ultrasonographic measurements.

\section{References}

[1] A. Khera, J.A. de Lemos, R.M. Peshock, H.S. Lo, H.G. Stanek, S.A. Murphy, F.H. Wians Jr et al., Relationship between Creactive protein and subclinical atherosclerosis: the Dallas Heart Study, Circulation 113(1) (3 Jan 2006), 38-43.
[2] M. Miller, M. Zhan and S. Havas, High attributable risk of elevated C-reactive protein level to conventional coronary heart disease risk factors: the Third National Health and Nutrition Examination Survey, Arch Intern Med 165(18) (10 Oct 2005), 2063-2068.

[3] M. van Oijen, J.C. Witteman, A. Hofman, P.J. Koudstaal and M.M. Breteler, Fibrinogen is associated with an increased risk of Alzheimer disease and vascular dementia, Stroke 36(12) (2005), 2637-2641.

[4] O. Rogowski, S. Toker, I. Shapira, S. Melamed, A. Shirom, D. Zeltser et al., Values of high-sensitivity C-reactive protein in each month of the year in apparently healthy individuals, $A m$ J Cardiol 95(1) (1 Jan 2005), 152-155.

[5] S. Berliner, O. Rogowski, S. Aharonov, T. Mardi, T. Tolshinsky, M. Rozenblat et al., Erythrocyte adhesiveness/aggregation: a novel biomarker for the detection of lowgrade internal inflammation in individuals with atherothrombotic risk factors and proven vascular disease, Am Heart $J$ 149(2) (Feb 2005), 260-267.

[6] D. Zeltser, O. Rogowski, T. Mardi, D. Justo, T. Tolshinsky, Y. Goldin et al., Clinical and laboratory characteristics of patients with atherothrombotic risk factors presenting with low concentrations of highly sensitive C-reactive protein, Atherosclerosis 176(2) (Oct 2004), 297-301.

[7] E.G. Grant, C.B. Benson, G.L. Moneta, A.V. Alexandrov, J.D. Baker, E.I. Bluth, B.A. Carroll, M. Eliasziw, J. Gocke, B.S. Hertzberg, S. Katarick, L. Needleman, J. Pellerito, J.F. Polak, K.S. Rholl, D.L. Wooster and E. Zierler, Society of Radiologists in Ultrasound. Carotid artery stenosis: grayscale and Doppler ultrasound diagnosis-Society of Radiologists in Ultrasound consensus conference, Ultrasound $Q$ 19(4) (Dec 2003), 190-198.

[8] International committee for standardization in hematology. Recommendation of measurement of erythrocyte sedimentation rate of human blood, Immunochemistry 2 (1965), 235254.

[9] A. Clauss, Gerinnungsphysiologische Schnellmethode zur Bestimmung des Fibrinogens, Acta Haematol Basel 17 (1957), $237-246$. 
[10] N. Rifai, R.P. Tracy and P.M. Ridker, Clinical efficacy of an automated high-sensitivity C-reactive protein assay, Clin Chem 45 (1999), 2136-2141.

[11] V. Schechner, I. Shapira, S. Berliner, D. Comanesther, T. Hershcovici, J. Orlin et al., Significant dominance of fibrinogen over immunoglobulins, C-reactive protein, cholesterol and triglycerides in maintaining increased red blood cell adhesiveness/aggregation: a model in hypercholaesterolemic patients, Eur J Clin Invest 33 (2003), 955-961.

[12] R. Gamzu, R. Rotstein, R. Fusman, D. Zeltser, A.S. Berliner and M.J. Kupferminc, Increased erythrocyte adhesiveness and aggregation in peripheral venous blood of women with pregnancy-induced hypertension, Obstet Gyneco.l 98 (2001), 307-312.

[13] S. Berliner, I. Shapira, O. Rogowski, N. Sadees, R. Rotstein, R. Fusman et al., Combined leukocyte and erythrocyte aggregation in the peripheral venous blood during sepsis. A clue to the presence of a commonly shared adhesive protein(s), Int $J$ Clin Lab Res 30 (2000), 27-31.

[14] Y. Sharshun, S. Brill, T. Mardi, D. Justo, M. Rozenblat, Y. Goldinn et al., Inflammation at a glance: erythrocyte adhesiveness/aggregation to reveal the presence of inflammation in individuals with atherothrombosis, Heart Dis 5 (2003), 182183.

[15] R. Rotstein, R. Fusman, D. Zeltser, I. Shapira, E. Shabtai, D. Avitzour et al., The picture of inflammation: a new concept that combines the white blood cell count and erythrocyte sedimentation rate into a new hematologic diagnostic modality, Acta Haematol 106(3) (2001), 106-114.

[16] P.J. Goldschmidt-Clermont, M.A. Creager, D.W. Lorsordo, G.K. Lam, M. Wassef and V.J. Dzau, Atherosclerosis 2005: recent discoveries and novel hypotheses, Circulation 112(21) (22 Nov 2005), 3348-3353.

[17] M.P. de Maat, E.M. Bladbjerg, T. Drivsholm, K. BorchJohnsen, L. Moller and J. Jespersen, Inflammation, thrombosis and atherosclerosis: results of the Glostrup study, J Thromb Haemost 1 (2003), 950-957.

[18] M.P. Reilly, M.L. Wolfe, A.R. Localio and D.J. Rader, Creactive protein and coronary artery calcification: The Study of Inherited Risk of Coronary Atherosclerosis (SIRCA), Arterioscler Thromb Vasc Biol 23 (2003), 1851-1856.

[19] R.F. Redberg, N. Rifai, L. Gee and P.M. Ridker, Lack of association of C-reactive protein and coronary calcium by electron beam computed tomography in postmenopausal women: implications for coronary artery disease screening, J Am Coll Cardiol 36 (2000), 39-43.

[20] M.E. Hunt, P.G. O’Malley, M.N. Vernalis, I.M. Feuerstein and A.J. Taylor, C-reactive protein is not associated with the presence or extent of calcified subclinical atherosclerosis, Am Heart J 141 (2001), 206-210.

[21] T.J. Wang, M.G. Larson, D. Levy, E.J. Benjamin, M.J. Kupka, W.J. Manning et al., C-reactive protein is associated with subclinical epicardial coronary calcification in men and women: the Framingham Heart Study, Circulation 106 (2002), 1189-1191.

[22] S. Hee Choi, H. Chang Kim, C. Woo Ahn, H. Keun Cho, B. Soo Cha, Y.S. Chung et al., Is high-sensitivity C-reactive protein associated with carotid atherosclerosis in healthy Koreans? Eur J Cardiovasc Prev Rehabil 12(6) (Dec 2005), 548-554.
[23] S. Kiechl, G. Egger, M. Mayr, C.J. Wiedermann, E. Bonora, F. Oberhollenzer et al., Chronic infections and the risk of carotid atherosclerosis: prospective results from a large population study, Circulation 103 (2001), 1064-1070.

[24] R. Blackburn, P. Giral, E. Bruckert, J.M. Andre, S. Gonbert, M. Bernard, M.J. Chapman and G. Turpin, Elevated Creactive protein constitutes an independent predictor of advanced carotid plaques in dyslipidemic subjects, Arterioscler Thromb Vasc Biol 21(12) (Dec 2001), 1962-1968.

[25] S. Makita, M. Nakamura and K. Hiramori, The association of C-reactive protein levels with carotid intima-media complex thickness and plaque formation in the general population, Stroke 36(10) (Oct 2005), 2138-2142.

[26] T.J. Wang, B.H. Nam, P.W. Wilson, P.A. Wolf, D. Levy, J.F. Polak, R.B. D'Agostino and C.J. O'Donnell, Association of C-reactive protein with carotid atherosclerosis in men and women: the Framingham Heart Study, Arterioscler Thromb Vasc Biol 22(10) (1 Oct 2002), 1662-1667.

[27] A. Khera, D.K. McGuire, S.A. Murphy, H.G. Stanek, S.R. Das, W. Vongpatanasin, F.H. Wians Jr, S.M. Grundy and J.A. de Lemos, Race and gender differences in C-reactive protein levels, J Am Coll Cardiol 46(3) (2 Aug 2005), 464-469.

[28] O. Rogowski, D. Zeltser, I. Shapira, M. Burke, V. Zakut, T. Mardi, E. Ben-Assayag, J. Serov, M. Rozenblat and S. Berliner, Gender difference in C-reactive protein concentrations in individuals with atherothrombotic risk factors and apparently healthy ones, Biomarkers 9(1) (Jan-Feb 2004), 85-92.

[29] E.B. Assayag, N.M. ornstein, I. Shapira, T. Mardi, Y. Goldin, T. Tolshinsky et al., Inflammation sensitive proteins and erythrocyte aggregation atherothrombosis, Int J Cardiol 98 (2005), 271-276.

[30] S. Berliner, R. Ben-Ami, D. Samocha-Bonet, S. Abu-Abeid, V. Schechner, Y. Beigel et al., The degree of red blood cell aggregation on peripheral blood glass slides corresponds to inter-erythrocyte cohesive forces in laminar flow, Thromb Res 114 (2004), 37-44.

[31] D. Zeltser, N.M. Bornstein, R. Rotstein, I. Shapira and S. Berliner, The erythrocyte adhesiveness/aggregation test in the peripheral blood of patients with ischemic brain events, Acta Neurol Scand 103 (2001), 316-319.

[32] D. Zeltser, R. Rotstein, O. Rogowski, R. Fusman, I. Shapira, V. Prochorov et al., The erythrocyte adhesiveness/aggregation (EAAT) in the peripheral blood of patients with ischemic heart and brain disease with normal fibrinogen concentrations, Appl Rheol 10 (2000), 231-237.

[33] T. Mardi, F. Aviv, R. Rotstein, R. Fusman, A. Roth, G. Keren et al., Detection of thrombolysis-related reduction in red blood cell adhesiveness/aggregation by using a simple slide test, Cardiology 97 (2002), 226-229.

[34] J. Danesh, S. Lewington, S.G. Thompson et al., Plasma fibrinogen level and the risk of major cardiovascular diseases and nonvascular mortality: an individual participant metaanalysis, JAMA 294(14) (12 Oct 2005), 1799-809.

[35] M. Fisher and H.J. Meiselman, Hemorheological factors in cerebral ischemia, Stroke 22(9) (Sep 1991), 1164-1169.

[36] S.S. Daskalopoulou, M.E. Daskalopoulos, D. Perrea, A.N. Nicolaides and C.D. Liapis, Carotid artery atherosclerosis: what is the evidence for drug action? Curr Pharm Des 13(11) (2007), 1141-1159. 


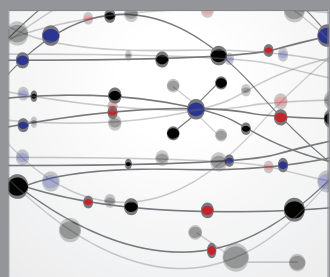

The Scientific World Journal
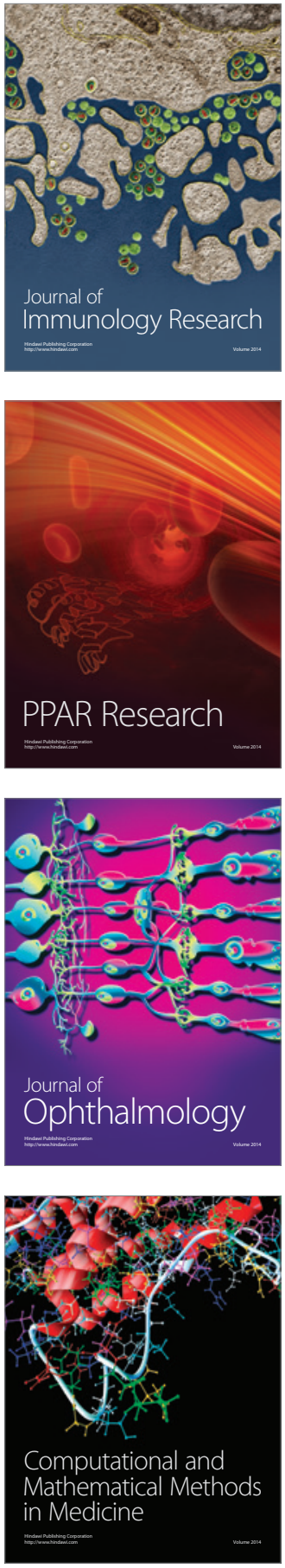

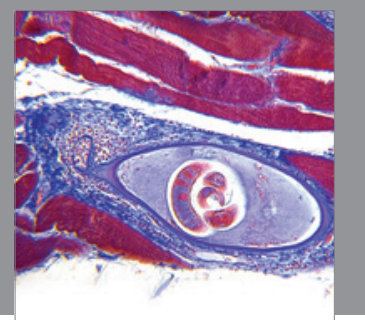

Gastroenterology

Research and Practice
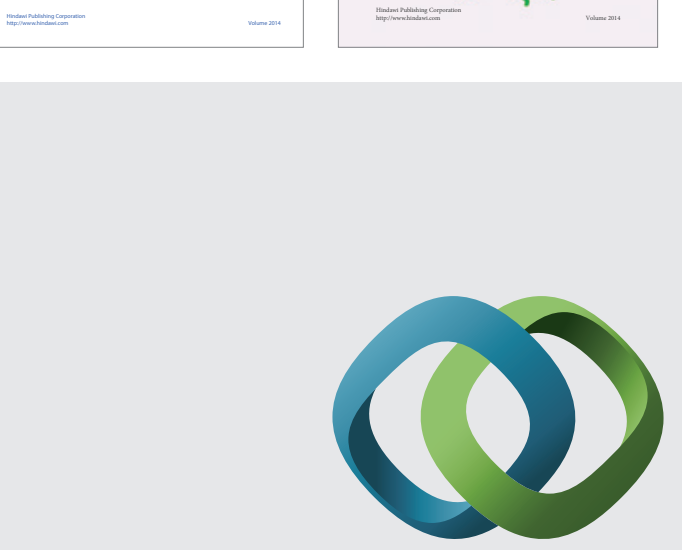

\section{Hindawi}

Submit your manuscripts at

http://www.hindawi.com
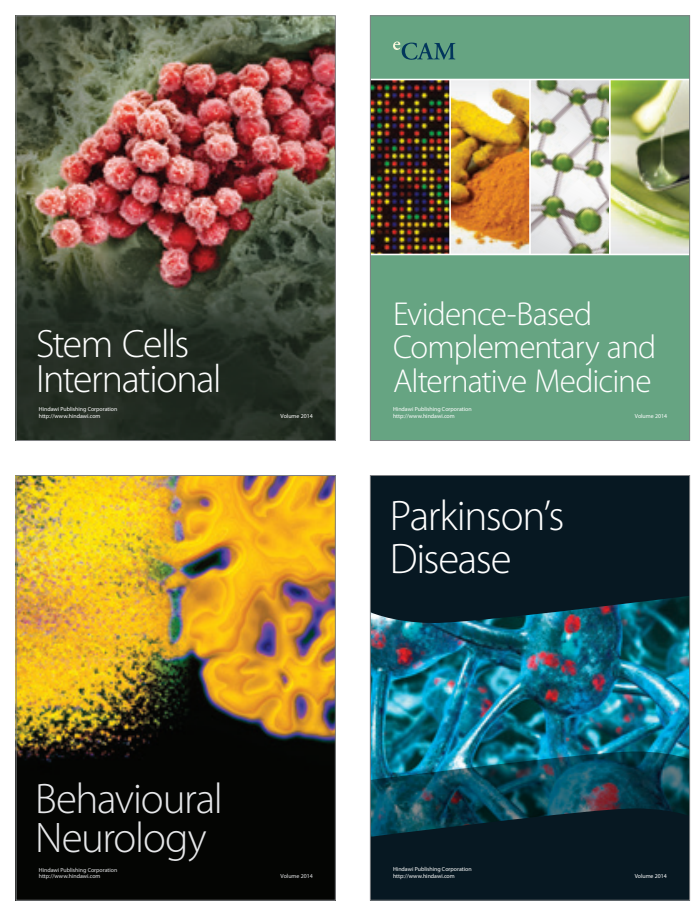

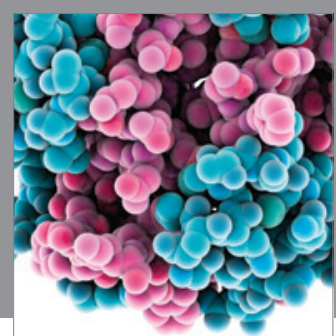

Journal of
Diabetes Research

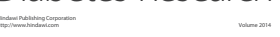

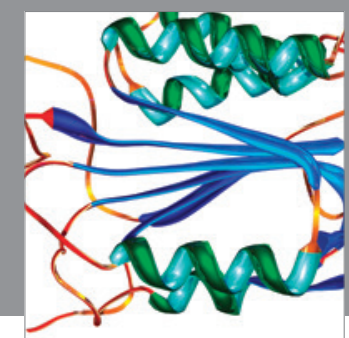

Disease Markers
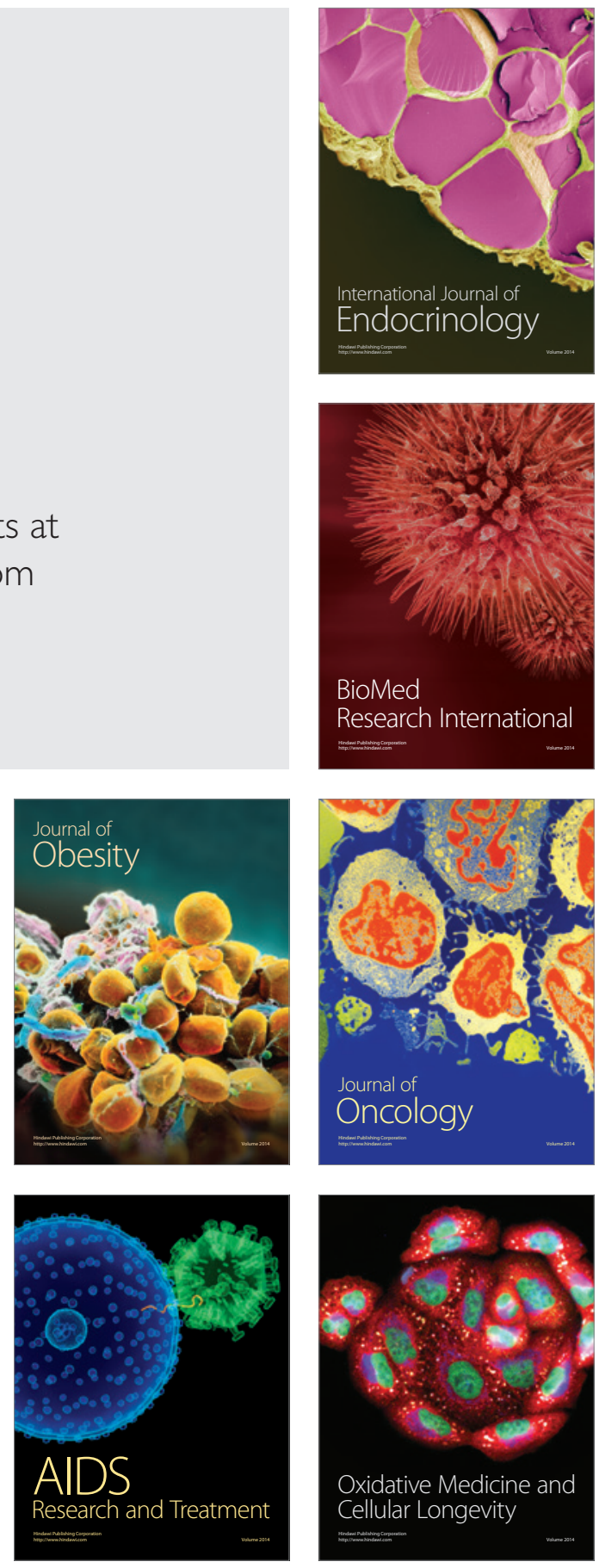